\title{
E-Cadherin as a Novel Surface Marker of Spermatogonial Stem Cells
}

\author{
E. N. Tolkunova ${ }^{a, b}$, A. B. Malashicheva ${ }^{a, b}$, E. V. Chikhirzhina ${ }^{a}$, E. I. Kostyleva ${ }^{a}$, \\ W. Zeng ${ }^{c}$, J. Luo ${ }^{c}$, I. Dobrinski ${ }^{c}$, A. Hierholzer ${ }^{b}$, R. Kemler ${ }^{b}$, and A. N. Tomilin ${ }^{a, b, *}$ \\ a Institute of Cytology, Russian Academy of Sciences, St. Petersburg, Russia \\ ${ }^{b}$ Planck Institute for Immunobiology, Freiburg, Germany \\ ${ }^{c}$ New Bolton Center, Veterinary School, University of Pennsylvania, United States \\ *e-mail: antom@mail.cytspb.rssi.ru \\ Received August 20, 2008
}

\begin{abstract}
Spermatogenesis is a fundamental biological process that ensures the transition of a gene from one ganeration to another via male gametes. This process relies on a rare population of testicular cells called spermatogonial stem cells (SSCs), which self-renew throughout adult male life and differentiate into mature gametes. Despite the longstanding study of SSCs, their biological properties remain largely unknown, which is partly due to the very limited availability of these cells. Here, we show that cell adhesion protein E-cadherin is a highly specific surface marker of mouse SSCs that can be successfully used to enrich them.
\end{abstract}

Key words: spermatogenesis, E-cadherin, spermatogonial stem cells.

DOI: $10.1134 / \mathrm{S} 1990519 \mathrm{X} 09020011$

Abbreviations: SSCs, spermatogonial stem cells; FCS, fetal calf serum; BSA, bovine serum albumin; PFA, paraformaldehyde; GFP, green fluorescent protein; hCG, human chorionic gonadotropin; Hprt, hypoxanthine guanine phosphorybosil transferase; PMS, pregnant mare serum; DAPI, 4',6-diamidino-2phenylindole; PBS, phosphate buffer solution; DMSO, dimethyl sulfoxide.

Spermatogenesis is a complex process of male gamete generation during the reproductive period and occurs in the epithelium of seminiferous tubules (de Rooij, 1998, 2001). Spermatogenesis is divided into three phases, i.e., mitosis, meiosis, and spermiogenesis. The mitotic phase is the period of spermatogonia reproduction. In mice, these cells are divided into morphological types that replace each other, including type A, In (intermediate), and type $\mathrm{B}$. Type $\mathrm{A}$ is subdivided into $\mathrm{A}_{\mathrm{S}}$ (single), $\mathrm{A}_{\mathrm{PR}}$ (paired), and $\mathrm{A}_{\mathrm{AL}}$ (aligned, 4-16 cell clusters) spermatogonia. During further steps of spermatogenesis $A_{A L}$ spermatogonia differentiate into $A_{1}$ spermatogonia, which in turn undergo six consecutive mitotic divisions $\left(\mathrm{A}_{2}, \mathrm{~A}_{3}, \mathrm{~A}_{4}, \mathrm{In}, \mathrm{B}\right)$ and become preleptotene spermatocytes that enter meiosis.

Undifferentiated $A$ type spermatogonia $\left(A_{S}, A_{P R}\right.$, and possibly $\mathrm{A}_{\mathrm{AL}}$ ) are regarded as spermatogonial stem cells (SSC) because they are able to colonize and restore spermatogenesis following transplantion into testes of spermatogenesis-deficient recipient mice (Yoshinaga et al., 1991; de Rooij et al., 1999; Ogawa et al., 2000; Ohta et al., 2000; Shinohara et al., 2000a). Recent studies showed that SSCs may be valuable for tissue replacement therapy in humans. It has been found that cultured mouse SSCs can turn into pluripotent cells that are functionally similar to embryonic stem cells (ESCs) (Kanatsu-Shinohara et al., 2004a; Guan et al., 2006).

Although SSCs hold great promises as a cell source for the tissue replacement therapy little is known about the regulation of their self-renewal and differentiation. It is known that the POU-domain transcription factor Oct4 is expressed in the type-A subpopulation of spermatogonia; however, its function in these cells has not yet been addressed (Pesce et al., 1998). The known factors required for SSC maintenance are promyelocyte leukemia Zinc-finger factor (PLZF or Zbtb16), Neurogenin3 and Sox3 (Buaas et al., 2004; Costoya et al., 2004; Yoshida et al., 2004; Raverot et al., 2005). These factors are localized in cell nuclei and are therefore of little use for enriching SSCs. Known surface markers are not particularly specific for SSCs and can only be applied to enrich the SSC population in combination with each other, essentially overcomplicating the procedure of SSC purification (Shinohara et al., 1999; Ohbo et al., 2003; Kanatsu-Shinohara et al., 2004b; Ryu et al., 2004). Thus, identifying a novel surface marker highly specific for SSCs seemed to be a highly relevant goal.

Cadherins represent a large family of transmembrane proteins that are involved in calcium-dependent 
homotypic cell interactions, as well as implicated in embryogenesis, morphogenesis, and malignant transformation. Cadherin extracellular domains ensure intercellular adhesion, whereas their intracellular domains are linked with the cytoskeleton by catenins, APC, and p120 proteins (Takeichi, 1995; Yap, 1998; Nollet et al., 2000; Stemmler, 2008). E-cadherin (also called Cdh1 or uvomorulin) is a key member of the family required for the development of trophectoderm, the earliest epithelium in mammalian embryogenesis (Larue et al., 1994). Later in development, its expression is observed in basically all epithelial tissues, including the epiblast and skin and intestinal epithelium (Stemmler, 2008). Furthermore, E-cadherin is essential for gametogenesis, a process that has been examined in the most detail in Drosophila. DE-cadherin is involved in oocyte stem cells anchored in niches formed by so-called cap cells. The loss of DEcadherin completely inhibits Drosophila oogenesis (Song et al., 2002). Furthermore, the level of DE-cadherin expression on oocyte stem cells directly correlates to their capacity to occupy a niche and, correspondingly, to retain stem cell properties (Jin et al., 2008).

DE-cadherin fulfils similar function of SSC anchoring also in drosophila testes. It has been shown that it is necessary to adjust stem cell division perpendicularly to the plane of the stem and hub cell contact to ensure asymmetric maternal cell division. Therefore, one daughter cell remains a stem cell and is retained in the niche, while the other one is displaced and is committed to differentiate into a mature gamete (Yamashita et al., 2003).

Mouse E-cadherin is involved in the determination and migration of primordial germ cells (PGCs), as well in the gonad formation, which supports PGS contacts (Bendel-Stenzel et al., 2000; Di Carlo and De Felici, 2000; Okamura et al., 2003). The data on E-cadherin expression in adult testes are rather controversial; some investigators failed to detect it in testes at all (Byers et al., 1994), whereas others found it in nearly all testicular cells (Andersson et al., 1994). Most likely, this discrepancy originated from the poor quality of antibodies used in each study.

In this work, we used highly specific antibodies against mouse E-cadherin and demonstrated that the protein is expressed specifically in SSCs of adult mice. We confirmed the conclusion by showing that E-cadherin-enriched germ cells can successfully colonize recipient testes.

\section{MATERIALS AND METHODS}

E-cadherin ${ }^{+}$-cell enrichment and transplantation. In our experiments, PBS buffer contained $\mathrm{Ca}^{2+}$ and $\mathrm{Mg}^{2+}$ to prevent extracellular E-cadherin domain loss from the cell surface. A single cell suspension from 68 -week-old mice testes was obtained according to the method described (Ogawa et al., 1997). Testes were isolated free of tunica albuginea. Released seminiferous tubules were incubated in ten volumes of PBS containing $10 \mathrm{mg} / \mathrm{ml}$ collagenase type IV (Sigma, United States) at $37^{\circ} \mathrm{C}$ for $15 \mathrm{~min}$ (complete tubule dissociation). The suspension was washed two to four times with 10 volumes of PBS by centrifugation $(5 \mathrm{~min}$, $1500 \mathrm{rpm}$ ), resuspended in $0.25 \%$ trypsin with $1 \mathrm{mM}$ EDTA, and incubated at $37^{\circ} \mathrm{C}$ for $5 \mathrm{~min}$. Trypsin was inactivated with $10 \%$ FCS in PBS. Further manipulations were performed on ice. Cells were counted and resuspended in the same buffer to a final density of $10 \times 10^{6}$ cells $/ \mathrm{ml}$. Cells were incubated in the blocking solution (PBS with $10 \%$ FCS) for $1 \mathrm{~h}$, then incubated for $1.5 \mathrm{~h}$ with gentle agitation with affinity-purified rabbit polyclonal antibodies against E-cadherin (Vestweber and Kemler, 1984; Brinster and Zimmermann, 1994) diluted to $1: 500$ in blocking solution. Cells were washed several times with chilled PBS, stained for $1 \mathrm{~h}$ on ice with goat antibodies to rabbit IgG, and conjugated with Alexa-488 (Molecular Probes, United States). After several washings, cells were counterstained with propidium iodide and sorted by flow cytometer MoFlo (DakoCytomation). Viable cell fractions (E-cadherin ${ }^{+}$and, as a control, E-cadherin ${ }^{-}$) were frozen in DMEM medium containing 10\% FCS and $10 \%$ DMSO. Immediately prior to transplantation, cells were thawed and their viability was determined by methylene blue staining. Cells were injected by a capillary needle into the testes of adult mice preliminarily treated with busulfan for 1 month to suppress their own spermatogenesis (Brinster and Avarbock, 1994; Brinster and Zimmermann, 1994; Brinster, 1998; Brinster et al., 2003). Two to four months after the transplantation testes were removed and fixed in $4 \%$ paraformaldehyde (PFA) and stained for galactosidase according to the routine technique.

Immunological staining. Mouse testes were fixed in $4 \%$ PFA at $4^{\circ} \mathrm{C}$ overnight, embedded into paraffin, and sectioned. Sections $(7-8 \mu \mathrm{m})$ were dewaxed with xylenes and rehydrated. Endogenous peroxidase was blocked 10 min with $3 \%$ hydrogen peroxide in methanol. Slides with sections were boiled for $20 \mathrm{~min}$ in buffer containing $40 \mathrm{mM}$ Tris- $\mathrm{HCl}, \mathrm{pH} 9.0$, and $1 \mathrm{mM}$ EDTA and slowly cooled to the room temperature. Testes sections were blocked isn $1 \%$ BSA in PBS and stained overnight at $4^{\circ} \mathrm{C}$ with affinity purified rabbit antibodies to E-cadherin (Vestweber and Kemler, 1984) diluted $1: 100$ in the same buffer supplemented with $0.1 \%$ Tween-20. Sections were subsequently incubated for $1 \mathrm{~h}$ at room temperature with EnVision-HRP rabbit reagent (DakoCytomation) and washed again with PBS. Peroxidase was visualized using DAB substrate (Sigma, United States). For immunofluorescent staining, monoclonal antibodiy to PLZF (1 : 100, Calbiochem, United States) were used as primary antibodies and goat antibodies to rabbit $\mathrm{IgG}$, conjugated with Alexa-488 (1 : 500, Molecular Probes, United States) were used as secondary. Stained sections were photo- 

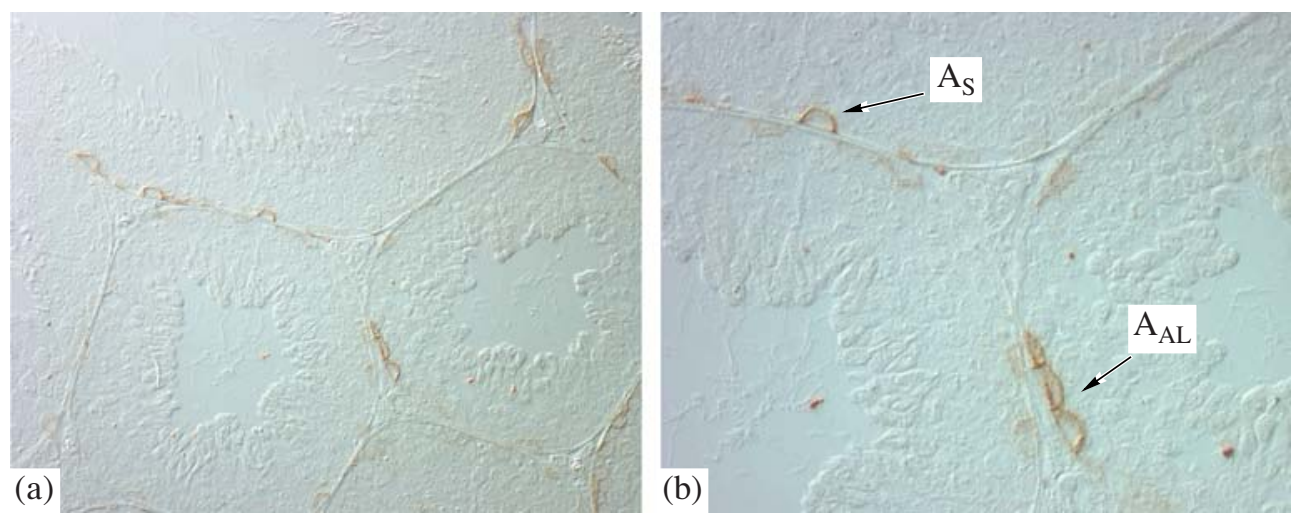

Fig. 1. E-cadherin expression in N57B16 adult mouse testes. Immunocolometric staining of testes paraffin sections with antibodies to E-cadherin. Arrows point to spermatogonia type single $\left(\mathrm{A}_{\mathrm{S}}\right)$ or aligned $\left(\mathrm{A}_{\mathrm{AL}}\right)$. Ob.: $10 \times(\mathrm{a})$ or $20 \times(\mathrm{b})$.

graphed under transmitted light with Nomarski differential interference contrast; immnofluorescent antibody-labeled sections were counterstained with DAPI and examined under Zeiss Axiovert 40 microscope equipped with a fluorescence module.

\section{RESULTS}

To clarify controversial data on E-cadherin expression in mouse adult testes we utilized affinity-purified antibodies to the extracellular domain of E-cadherin. Immunoenzyme staining of mouse adult testes sections revealed a specific pattern of signal distribution along the basal membrane that is typical for SSC. Cells expressing E-cadherin were found either as single cells or as chains on the basal membrane of testicle tubules (Fig. 1). Based on the literature data, we assumed that these cells are bona fide SSCs.

The most accurate functional proof of the presence of SSCs in testicular suspension and its quantitative evaluation is the transplantation developed by Brinster and coworkers (Brinster and Avarbock, 1994; Brinster and Zimmermann, 1994; Brinster, 1998; Brinster et al., 2003). The method is based on SSCs capacity to colonize the testes of recipient males and initiate the entire spermatogenesis process. Males of recipient mice were preliminarily treated with busulfan to reversibly suppress their own spermatogenesis. The injected cell suspension was usually derived from genetically marked donor mice (e.g., from ROSA26 mice expressing $\beta$-galactosidase), which allowed us to easily visualize donor-derived cells in recipient mice through appropriate staining. Then, $8-12$ weeks after injection, i.e., after a period long enough for non-SSC donor germ cells (including A1-A4- and B-spermagonia) to differentiate and leave the testicular epithelium via the natural spermatogenesis process, colonies expressing galactosidase were counted. It is widely accepted that only SSCs can give rise to these colonies; their number enables an quantitative estimation of the SSC enrichment in the injected cellular suspension.

To prove that transplanted cells expressing E-cadherin are true stem cells, the testicular cell suspension was preliminary enriched by flow cytometry. Figure $2 \mathrm{a}$ (left panel) depicts a typical size scatter of an adult testes cell suspension. According to the literature data (Shinohara et al., 2000a), the most SSC-enriched area is R1. To determine whether these cells express E-cadherin, we analyzed R1 population and found that about $4 \%$ of cells from this area expressed E-cadherin (Fig. 2a, right panel, population R3). It is notable that the number of E-cadherin ${ }^{+}$cells increased to $38 \%$ when cryptorchid mice were used as a source of testicular cells (Fig. 2b), which is in a good agreement with the data reported elsewhere (Shinohara et al., 2000a). The R3 area represents the rather uniform population of small, round cells and, as expected, consisted primarily of E-cadherin ${ }^{+}$cells (Fig. 2c).

R2 and R3 fraction cells were frozen and stored in liquid nitrogen or on dry ice. Cells were thawed immediately before injection into busulfan-treated recipient male testes. Viability of thawed cells was rather low (about 1-2\%). Nevertheless, 1600 viable cells from fraction R3 (E-cadherin ${ }^{+}$) grafted into the recipient testes produced $5 \mathrm{gal}^{+}$colonies (Fig. 2d), i.e. 1 colony per 300 injected cells, which is about twice as efficient compared to the standard multistep Thy-1 antibodybased procedure (Kubota et al., 2003). In contrast, more than $10^{4}$ viable cells of the $\mathrm{R} 2$ fraction injected into the recipient mouse produced no $\mathrm{gal}^{+}$-colonies. Thus, our results demonstrate that the $\mathrm{R} 3$ fraction is substantially enriched with SSCs; therefore, E-cadherin does in fact represent a novel surface marker that can be applied to sort cells. However, further work is required to improve cell viability during freezing.

It was reported that SSCs express the transcriptional repressor PLZF, which is necessary for their maintenance (Buaas et al., 2004; Costoya et al., 2004). We per- 

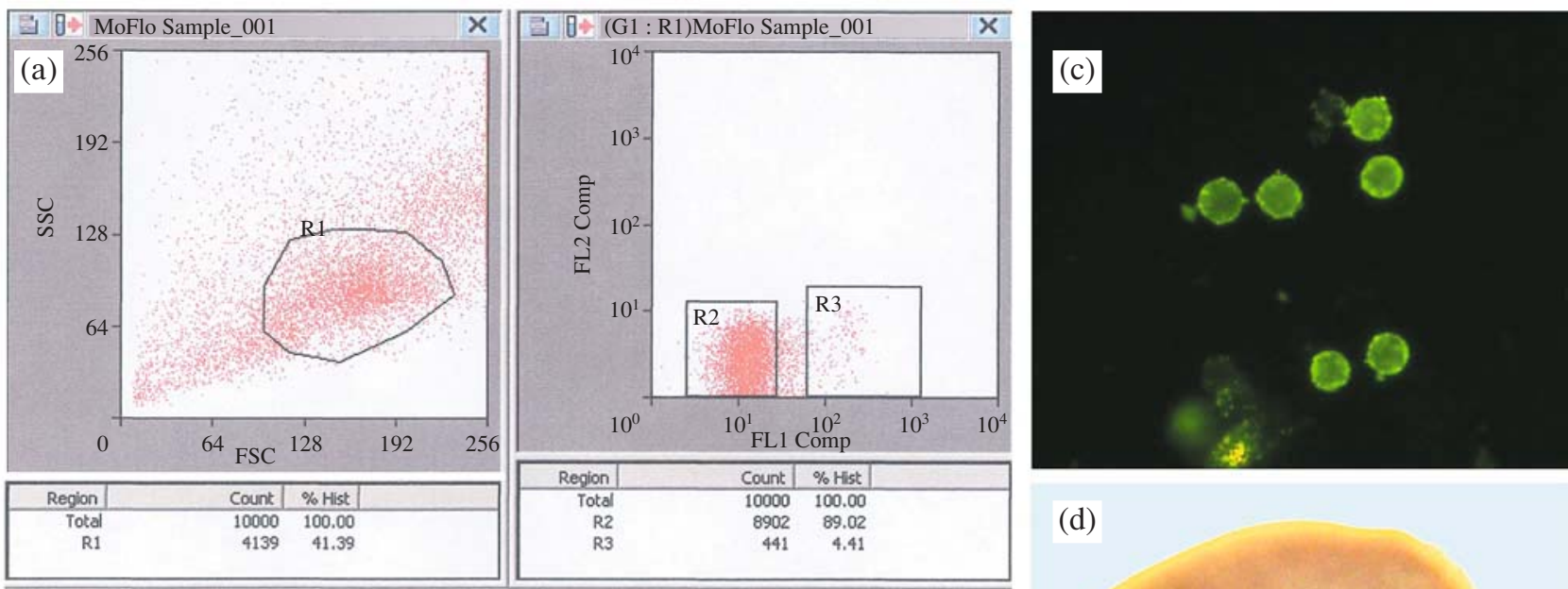

(d)
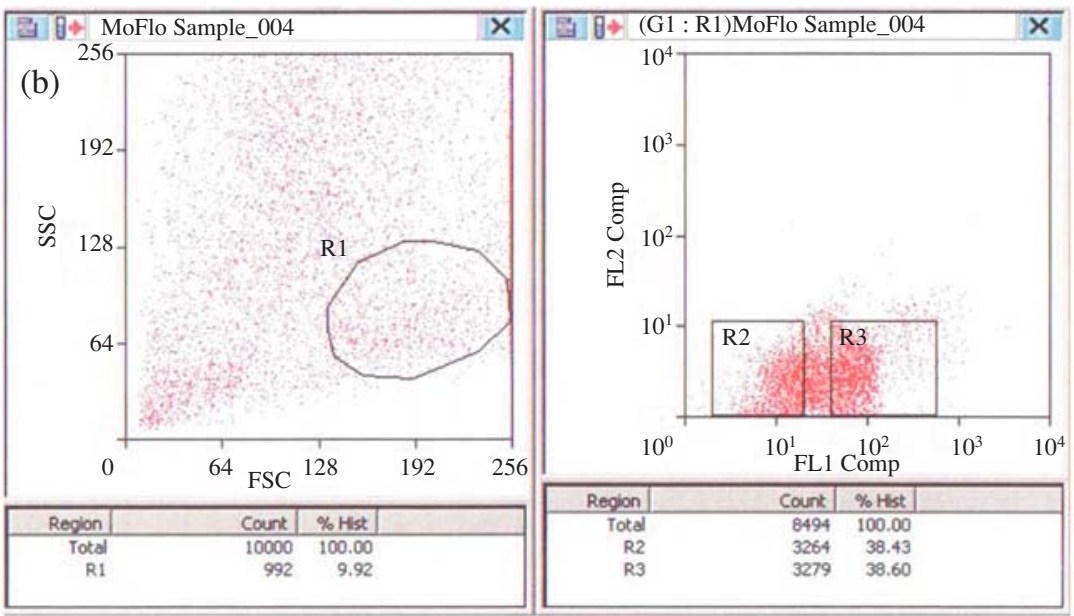

Fig. 2. E-cadherin ${ }^{+}$-cell sorting and transplantation.

(a, left panel) single cell suspension of adult mouse testicular cells stained with propidium iodide and antibodies to E-cadherin protein was sorted by the cell size; FSC-forward scattering; SSC-side scattering; (a, right panel) R1 fraction enriched with SSCs (Shinohara et al., 2000b) was further separated by flow cytometry into R3 and R2 fractions expressing E-cadherin. X axis-intensity of E-cadherin/Alexa-488 staining, relative units; Y axis-intensity of propidium iodide incorporation, relative units; (b) the same enrichment technique applied for the cell suspension derived from ROSA26 cryptorchid males; (c) fluorescence of $\mathrm{E}^{+}$-cadherin cells (fraction R3) immediately after the sorting; (d) recipient testes stained for galactosidase 2 months after transplantation $\mathrm{E}^{+}$-cadherin cells. Arrows indicate colonies derived from single ROSA26 SSC transplanted cells.

formed double immunofluorescent labeling of mouse testes and the E-cadherin ${ }^{+}$- cell suspension and found that E-cadherin and PLZF are frequently coexpressed in the same subpopulation of testicular cells (Fig. 3). These results provide additional evidence that E-cadherin represents a novel SSC marker.

\section{DISCUSSION}

In this study, we demonstrate that the E-cadherin protein is expressed in undifferentiated type-A spermatogonia (SSCs) in adult mouse testes. The low number of E-cadherin-expressing cells; their localization along the basal membrane as single cells or in chains of cells; the co-expression of E-cadherin with known PLZF marker; and, most critically, the ability of E-cad- herin $^{+}$to colonize recipient mouse testes with a high efficiency form a compelling argument that E-cadherin represents a novel SSC marker. Furthermore, our data show that this new marker is highly suitable for SSC enrichment from a testicular suspension. The new efficient approach to SSC isolation might find a range of useful applications, most notably those aimed at tissue replacement therapy (Kanatsu-Shinohara et al., 2004a; Guan et al., 2006). It should be noted that, during the preparation of this paper, similar data on E-cadherin expression in SSCs was published (Tokuda et al., 2007).

It would be highly relevant pursuit to assess E-cadherin's role in SSC self-renewal and differentiation based on the loss of function. As E-cadherin homozygous mouse embryos fail to survive beyond the blasto- 

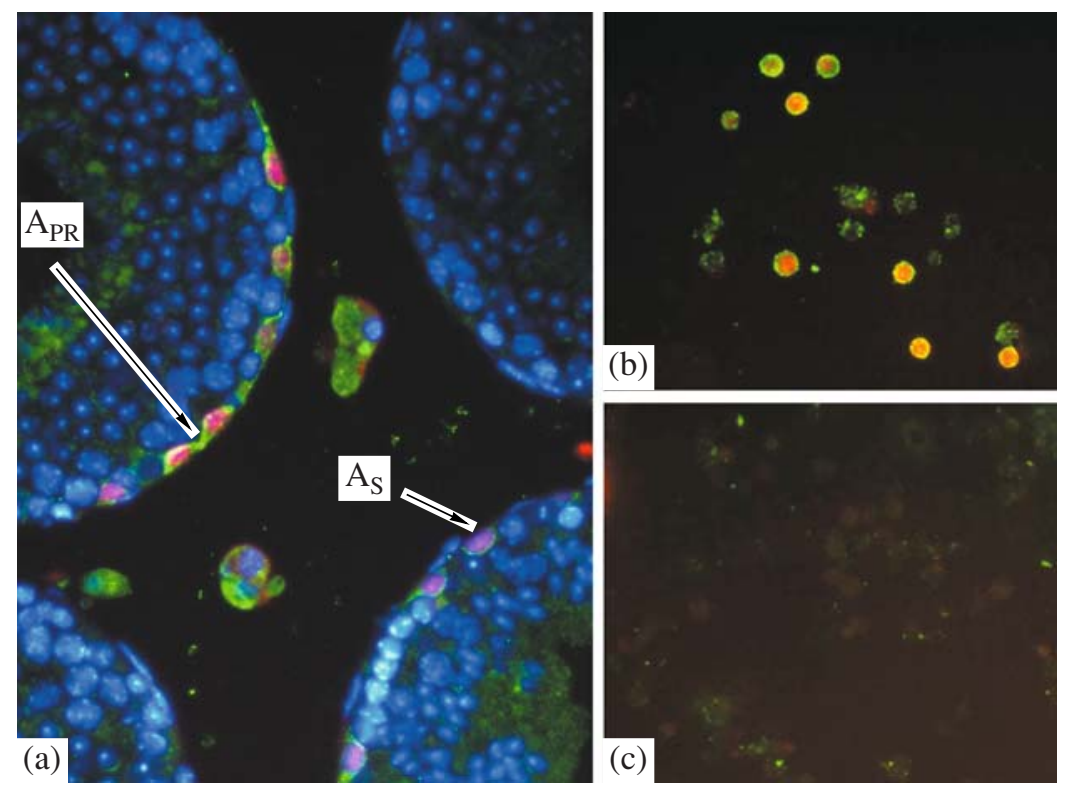

Fig. 3. Coexpression of E-cadherin and PLZF factor in mouse SSCs.

(a) Double immunofluorescence of adult testes paraffin sections stained with antibodies to E-cadherin (green) and PLZF (red); nuclear DNA was stained with DAPI (blue); (b) testicular E-cadherin ${ }^{+}$-cells after sorting (see, Fig. 2, fraction R3) stained with antibodies to PLZF (red); (c) negative control: testicular E-cadherin-cells after sorting (see Fig. 2, fraction R2) stained with antibodies to E-cadherin and PLZF; arrows point to spermatogonia type $\mathrm{A}_{\mathrm{S}}$ (single) or $\mathrm{A}_{\mathrm{PR}}$ (paired).

cyst stage (Larue et al., 1994), the method of conditioned knockout with a Cre/lox system should be deployed. However, because it is highly labor- and budget-consuming, we will attempt to elucidate E-cadherin function in SSC combining RNA-interference and lentivirus techniques. To this end, we have constructed lentiviruses that encode small hairpin (sh)RNAs complimentary to E-cadherin RNA. Preliminary tests showed that E-cadherin RNA and protein levels were significantly reduced in epithelial cells infected with this virus. SSC infection in vivo via viral injection in adult testes is not feasible without the temporary disruption of the blood-testicular barrier made and maintained by Sertoli cells. This barrier separates the near-basal membrane, SSC-containing, and luminal (carrying injected lentivirus) parts of the seminiferous epithelium and is not permeable for lentiviral particles (Kanatsu-Shinohara et al., 2004c). Therefore, to clarify the function of E-cadherin in SSCs it seems very important to develop a method of disrupting the barrier using chemical agents, which is currently a part of our effort.

Studying mechanisms of E-cadherin functioning in SSC is also an important pursuit. It is interesting to elucidate whether this protein is only implicated in intercellular adhesion and therefore retains SSCs in the testicular niche, or if it is also engaged in intracellular signaling. For example, E-cadherin may interact with cytoplasmic $\beta$-catenin and, therefore, may affect Wntsignaling pathway (Gavard and Mege, 2005). Furthermore, there is evidence that the interaction of E-cadherin with p120ctn protein releases the latter from the complex with the nuclear protein Kaiso (van Roy and McCrea, 2005; Daniel, 2007). Finally, E-cadherin signaling function in SSCs may be mediated through its interaction with tyrosine kinase receptors (Reshetnikova et al., 2007). To clarify how E-cadherin functions, we constructed E-cadherin proteins that contained mutations in different domains that are involved in the protein-protein interactions described above. Determining which mutant(s) is unable to fulfill the function of a wild-type protein in vivo or in cultured SSCs should help to dissect the how this protein functions in testes.

These studies should give greater insight into the how SSC self-renew differentiate and will undoubtedly be of fundamental and practical importance.

\section{ACKOWLEDGMENTS}

The work was supported primarily by grant $07-04-$ 01154 and partially by grant $07-04-92281$ from the Russian Foundation for Basic Research. Additionally, this study was supported by the Max Plank Society (Germany) and the program "Molecular and Cell Biology" (Russian Academy of Sciences).

\section{REFERENCES}

Andersson, A.M., Edvardsen, K., and Skakkebaek, N.E., Expression and Localization of $\mathrm{N}$ - and E-Cadherin in the Human Testis and Epididymis, Int. J. Androl., 1994, vol. 17, pp. 174-180. 
Bendel-Stenzel, M.R., Gomperts, M., Anderson, R., Heasman, J., and Wylie, C., The Role of Cadherins during Primordial Germ Cell Migration and Early Gonad Formation in the Mouse, Mech. Dev., 2000, vol. 69, pp. 412-420.

Brinster, R.L. and Avarbock, M.R., Germline Transmission of Donor Haplotype Following Spermatogonial Transplantation, Proc. Natl. Acad. Sci. USA, 1994, vol. 91, pp. $11303-$ 11307.

Brinster, C.J., Ryu, B.Y., Avarbock, M.R., Karagenc, L., Brinster, R.L., and Orwig, K.E., Restoration of Fertility by Germ Cell Transplantation Requires Effective Recipient Preparation, Biol. Reprod., 2003, vol. 69, pp. 412-420.

Brinster, R.L. and Zimmermann, J.W., Spermatogenesis Following Male Germ-Cell Transplantation, Proc. Natl. Acad. Sci. USA, 1994, vol. 91, pp. 11298-11302.

Brinster, R.L., Embryo Culture, Stem Cells and Experimental Modification of the Embryonic Genome. An Interview with Professor Ralph Brinster. Interview by Juan Arechaga, Int. J. Dev. Biol., 1998, vol. 42, pp. 861-878.

Buaas, F.W., Kirsh, A.L., Sharma, M., McLean, D.J., Morris, J.L., Griswold, M.D., de Rooij, D.G., and Braun, R.E., Plzf is Required in Adult Male Germ Cells for Stem Cell Self-Renewal, Nat. Genet., 2004, vol. 36, pp. 647-652.

Byers, S.W., Sujarit, S., Jegou, B., Butz, S., Hoschutzky, H., Herrenknecht, K., MacCalman C., and Blaschuk, O.W., Cadherins and Cadherin-Associated Molecules in the Developing and Maturing Rat Testis, Endocrinology, 1994, vol. 134, pp. 630-639.

Costoya, J.A., Hobbs, R.M., Barna, M., Cattoretti, G., Manova, K., Sukhwani, M., Orwig, K.E., Wolgemuth, D.J., and Pandolfi, P.P., Essential Role of Plzf in Maintenance of Spermatogonial Stem Cells, Nat. Genet., 2004, vol. 36, pp. 653-659.

Daniel, J.M., Dancing in and out of the Nucleus : p120(ctn) and the Transcription Factor Kaiso, Biochim. Biophys. Acta, 2007, vol. 1773, pp. 59-68.

de Rooij, D.G., Okabe, M., and Nishimune, Y., Arrest of Spermatogonial Differentiation in Jsd/Jsd, S117H/S117H, and Cryptorchid Mice, Biol. Reprod., 1999, vol. 61, pp. 842847.

de Rooij, D.G., Proliferation and Differentiation of Spermatogonial Stem Cells, Reproduction, 2001, vol. 121, pp. 347-354.

de Rooij, D.G., Stem Cells in the Testis, Int. J. Exp. Pathol., 1998, vol. 79, pp. 67-80.

Di Carlo, A. and De Felici, M., A Role for E-Cadherin in Mouse Primordial Germ Cell Development, Dev. Biol., 2000, vol. 226, pp. 209-219.

Gavard, J. and Mege, R.M., Once Upon a Time There Was beta-Catenin in Cadherin-Mediated Signalling, Biol. Cell., 2005, vol. 97, pp. 921-926.

Guan, K., Nayernia, K., Maier, L.S., Wagner, S., Dressel, R., Lee, J.H., Nolte, J., Wolf, F., Li, M., Engel, W., and Hasenfuss, G., Pluripotency of Spermatogonial Stem Cells from Adult Mouse Testis, Nature, 2006, vol. 440, pp. 1199-1203. Jin, Z., Kirilly, D., Weng, C., Kawase, E., Song, X., Smith, S., Schwartz, J., and Xie, T., Differentiation-Defective Stem Cells Outcompete Normal Stem Cells for Niche Occupancy in the Drosophila Ovary, Cell. Stem Cell, 2008, vol. 2, pp. 39-49.

Kanatsu-Shinohara, M., Inoue, K., Lee, J., Yoshimoto, M., Ogonuki, N., Miki, H., Baba, S., Kato, T., Kazuki, Y.,
Toyokuni, S., Toyoshima, M., Niwa, O., Oshimura, M., Heike, T., Nakahata, T., Ishino, F., Ogura, A., and Shinohara, T., Generation of Pluripotent Stem Cells from Neonatal Mouse Testis, Cell, 2004a, vol. 119, pp. 1001-1012.

Kanatsu-Shinohara, M., Toyokuni, S., and Shinohara, T., CD9 is a Surface Marker on Mouse and Rat Male Germline Stem Cells, Biol. Reprod., 2004b, vol. 70, pp. 70-75.

Kanatsu-Shinohara, M., Toyokuni, S., and Shinohara, T., Transgenic Mice Produced by Retroviral Transduction of Male Germ Line Stem Cells in Vivo, Biol. Reprod., 2004c, vol. 71, pp. 1202-1207.

Kubota, H., Avarbock, M.R., and Brinster, R.L., Spermatogonial Stem Cells Share Some, but Not All, Phenotypic and Functional Characteristics with Other Stem Cells, Proc. Natl. Acad. Sci. USA, 2003, vol. 100, pp. 6487-6492.

Larue, L., Ohsugi, M., Hirchenhain, J., and Kemler, R., E-Cadherin Null Mutant Embryos Fail to Form a Trophectoderm Epithelium, Proc. Natl. Acad. Sci. USA, 1994, vol. 91, pp. 8263-8267.

Nollet, F., Kools, P., and van Roy, F., Phylogenetic Analysis of the Cadherin Superfamily Allows Identification of Six Major Subfamilies Besides Several Solitary Members, J. Mol. Biol., 2000, vol. 299, pp. 551-572.

Ogawa, T., Arechaga, J.M., Avarbock, M.R., and Brinster, R.L., Transplantation of Testis Germinal Cells into Mouse Seminiferous Tubules, Int. J. Dev. Biol., 1997, vol. 41, pp. 111-122.

Ogawa, T., Dobrinski, I., Avarbock, M.R., and Brinster, R.L., Transplantation of Male Germ Line Stem Cells Restores Fertility in Infertile Mice, Nat. Med., 2000, vol. 6, pp. 24-29.

Ohbo, K., Yoshida, S., Ohmura, M., Ohneda, O., Ogawa, T., Tsuchiya, H., Kuwana, T., Kehler, J., Abe, K., Scholer, H.R., and Suda, T., Identification and Characterization of Stem Cells in Prepubertal Spermatogenesis in Mice Small Star, Filled, Dev. Biol., 2003, vol. 258, pp. 209-225.

Ohta, H., Yomogida, K., Dohmae, K., and Nishimune, Y., Regulation of Proliferation and Differentiation in Spermatogonial Stem Cells : the Role of C-Kit and Its Ligand SCF, Development, 2000, vol. 127, pp. 2125-2131.

Okamura, D., Kimura, T., Nakano, T., and Matsui, Y., Cadherin-Mediated Cell Interaction Regulates Germ Cell Determination in Mice, Development, 2003, vol. 130, pp. 64236430.

Pesce, M., Wang, X., Wolgemuth, D.J., and Scholer, H., Differential Expression of the Oct-4 Transcription Factor During Mouse Germ Cell Differentiation, Mech. Dev., 1998, vol. 71, pp. 89-98.

Raverot, G., Weiss, J., Park, S.Y., Hurley, L., and Jameson, J.L., Sox3 Expression in Undifferentiated Spermatogonia is Required for the Progression of Spermatogenesis, Dev. Biol., 2005, vol. 283, pp. 215-225.

Reshetnikova, G., Troyanovsky, S., and Rimm, D.L., Definition of a Direct Extracellular Interaction between Met and E-Cadherin, Cell. Biol. Int., 2007, vol. 31, pp. 366-373.

Ryu, B.Y., Orwig, K.E., Kubota, H., Avarbock, M.R., and Brinster, R.L., Phenotypic and Functional Characteristics of Spermatogonial Stem Cells in Rats, Dev. Biol., 2004, vol. 274, pp. 158-170.

Shinohara, T., Avarbock, M.R., and Brinster, R.L., Beta1and Alpha6-Integrin Are Surface Markers on Mouse Spermatogonial Stem Cells, Proc. Natl. Acad. Sci. USA, 1999, vol. 96, pp. 5504-5509. 
Shinohara, T., Avarbock, M.R., and Brinster, R.L., Functional Analysis of Spermatogonial Stem Cells in Steel and Cryptorchid Infertile Mouse Models, Dev. Biol., 2000a, vol. 220, pp. 401-411.

Shinohara, T., Orwig, K.E., Avarbock, M.R., and Brinster, R.L., Spermatogonial Stem Cell Enrichment by Multiparameter Selection of Mouse Testis Cells, Proc. Natl. Acad. Sci. USA, 2000b, vol. 97, pp. 8346-8351.

Song, X., Zhu, C.H., Doan, C., and Xie, T., Germline Stem Cells Anchored by Adherens Junctions in the Drosophila Ovary Niches, Science, 2002, vol. 296, pp. 1855-1857.

Stemmler, M.P., Cadherins in Development and Cancer, Mol. Biosyst., 2008, vol. 4, pp. 835-850.

Takeichi, M., Morphogenetic Roles of Classic Cadherins, Curr. Opin. Cell. Biol., 1995, vol. 7, pp. 619-627.

Tokuda, M., Kadokawa, Y., Kurahashi, H., and Marunouchi, T., CDH1 Is a Specific Marker for Undifferentiated Spermatogonia in Mouse Testes, Biol. Reprod., 2007, vol. 76, pp. 130-141.

van Roy, F.M. and McCrea, P.D., A Role for Kaiso-p120ctn Complexes in Cancer, Nat. Rev. Cancer., 2005, vol. 5, pp. 956-964.
Vestweber, D. and Kemler, R., Rabbit Antiserum Against a Purified Surface Glycoprotein Decompacts Mouse Reimplantation Embryos and Reacts with Specific Adult Tissues, Exp. Cell. Res., 1984, vol. 152, pp. 169-178.

Yamashita, Y.M., Jones, D.L., and Fuller, M.T., Orientation of Asymmetric Stem Cell Division by the APC Tumor Suppressor and Centrosome, Science, 2003, vol. 301, pp. 15471550.

Yap, A.S., The Morphogenetic Role of Cadherin Cell Adhesion Molecules in Human Cancer: A Thematic Review, Cancer. Invest., 1998, vol. 16, pp. 252-261.

Yoshida, S., Takakura, A., Ohbo, K., Abe, K., Wakabayashi, J., Yamamoto, M., Suda, T., and Nabeshima, Y., Neurogenin3 Delineates the Earliest Stages of Spermatogenesis in the Mouse Testis, Dev. Biol., 2004, vol. 269, pp. 447458.

Yoshinaga, K., Nishikawa, S., Ogawa, M., Hayashi, S., Kunisada, T., Fujimoto, T., and Nishikawa, S., Role of C-kit in Mouse Spermatogenesis : Identification of Spermatogonia as a Specific Site of C-kit Expression and Function, Development, 1991, vol. 113, pp. 689-699. 